\title{
Arsenic sorption by red mud- modified biochar produced from rice straw
}

by Chuan, W., Huang, L., Xue, S., Hartley, W., Cui, M. and Wong, $\mathrm{M}$.

Copyright, Publisher and Additional Information: This is the author accepted manuscript. The final published version (version of record) is available online via Springerlink

Please refer to any applicable terms of use of the publisher.

DOI: https://doi.org/10.1007/s11356-017-9466-7

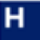

Harper Adams University

Chuan, W., Huang, L., Xue, S., Hartley, W., Cui, M. and Wong, M. 2017. Arsenic sorption by red mudmodified biochar produced from rice straw. Environmental Science and Pollution Research 
1 Arsenic sorption by red mud-modified biochar produced from rice

2 straw

3 Chuan Wu $\mathrm{Wu}^{\mathrm{a}}$, Liu Huang ${ }^{\mathrm{a}}$, Sheng-Guo Xue ${ }^{\mathrm{a}^{*}}$, Li-Zheng Shi ${ }^{\mathrm{a}}$, William Hartley ${ }^{\mathrm{b}}$,

$4 \quad$ Mengqian Cui ${ }^{\mathrm{a}}$, Ming-Hung Wong ${ }^{\mathrm{c}, \mathrm{d}}$

5

a School of Metallurgy and Environment, Central South University, Changsha

$6 \quad$ 410083, PR China

7

b Crop and Environment Sciences Department, Harper Adams University,

8

9 20 1 22

Newport, Shropshire, TF10 8NB, United Kingdom

${ }^{c}$ Consortium on Health, Environment, Education and Research (CHEER), The Education University of Hong Kong,, Tai Po, Hong Kong Special Administrative Region, PR China

${ }^{\mathrm{d}}$ School of Environment, Jinan University, Guangzhou, PR China

* Corresponding author:

Tel: +86-13787148441. E-mail address: sgxue@csu.edu.cn. 9 
24

\section{Abstract}

Rice straw biochar modified with red mud (RM-BC) is used here as an adsorbent to remove As from aqueous solutions. Rice straw is an agricultural waste material whilst red mud is a waste product from bauxite processing. SEM-EDS and XRD analyses demonstrated that red mud had distributed successfully on the surface of the rice straw biochar. With increasing solution $\mathrm{pH}$, arsenate adsorbtion on $\mathrm{RM}-\mathrm{BC}$ decreased whilst As(III) increased. Arsenate adsorption kinetics on RM-BC fitted the pseudo-second-order model, whilst that of As(III) favored the Elovich model. All sorption isotherms produced superior fits with the Langmuir model. RM-BC exhibited improved As removal capabilities, with a maximum adsorption capacity (Qmax) for As(V) of 5923 ug 9 -1, approximately ten times greater than that of the untreated BC (552.0 ug•g-1). Furthermore, X-ray absorption near-edge spectroscopy (XANES) indicated that adsorption of $\mathrm{As}(\mathrm{V})$ on $\mathrm{RM}-\mathrm{BC}$ was possibly due to surface complexation and electrostatic interactions. RM-BC may be used as a valuable adsorbent for removing As due to the waste materials being relatively abundant.

\section{Keywords: Biochar; Red mud; Pyrolysis; Arsenic; XANES}

(1)




\section{Introduction}

Arsenic (As) has been recognized as 'a known carcinogen' by the World Health

Organization (WHO) (WHO, 2001). Many anthropogenic activities including the use of insecticides, herbicides and phosphate fertilizers, semi-conductor industries, mining and smelting operations, industrial processes, coal combustion and timber preservatives have released As into soils and groundwater causing global concern (Kim et al., 2014; Yu et al., 2015). Arsenic-contaminated soils are harmful to food safety and groundwater quality, and eventually threaten human health in many regions of the world such as Mexico, USA, China, Bangladesh and Pakistan (Jadhav et al., 2015; Wu et al., 2016a). In soil, As compounds exist either as inorganic and organic species. Generally, inorganic As species (arsenite $\mathrm{As}(\mathrm{III})$ and arsenate $\mathrm{As}(\mathrm{V})$ ) are more toxic than organic forms to living organisms (Beesley et al., 2014).

Red mud (RM) is an alkaline waste by-product generated from the extraction of alumina from bauxite during the Bayer process. Due to the very large volumes of red mud (120 million tons per year) and difficulty with its disposal, it is essential to find alternative options for its treatment and use (Klauber et al., 2011). Generally, the mineralogical composition of red mud consists of various forms of iron and aluminum oxides, calcium and sodium aluminum silicates and numerous titanium compounds. Red mud has a fine, porous structural nature and its surface carries significant hydroxyl groups (Liu and Naidu, 2014). As a result, the material has great potential to 
remediate As contamination both in soils and groundwater (Altundogan, 2000; Klauber et al., 2011; Lopes et al., 2013). Previous studies confirmed that red mud, or neutralized red mud, can remove As from aqueous solutions (Altundogan, 2000; Genc, 2003). Furthermore, it has been demonstrated that RM can influence As fractionation in soils (Lee et al., 2011; Yan et al., 2013). The interaction mechanisms between As and red mud can be mainly attributed to electrostatic attraction/repulsion, chemical interaction (Castaldi et al., 2010; Wu et al., 2016b; Rubinos et al., 2005).

Biochar is a stable solid produced by thermal or hydrothermal conversion of carbonaceous biomass under oxygen-limiting conditions (Zhang et al., 2013). It has been used in numerous applications mostly as a soil amendment/conditioner, a waste management tool and to mitigate global warming (Ahmad et al., 2014). Furthermore, biochar may improve soil fertility, increase soil nutrient bioavailability, improve agricultural productivity and sequester carbon (Lone et al., 2015). Nevertheless it has been shown that biochar may also reduce the bioavailability of essential plant micronutrients (Hartley, 2016). Additionally, biochar can effectively remove water contaminants (such as As, $\mathrm{Cr}$ and $\mathrm{Cd}$ ) because of its favorable physicochemical properties (large surface area and porous structure) (Tan et al., 2016). It has also been reported that the characteristics of biochar, mainly the large surface area and cation exchange capacity (CEC), can lead to the stabilization of many heavy metals in the environment (Gregory et al., 2014).

Conversely, it has been demonstrated that biochar can elevate soil $\mathrm{pH}$ and thus mobilize As, which has limited its application in As remediation (Hartley et al., 2009; 
Beesley et al., 2014). Recent studies have focused on the application of biochar-based materials, particularly biochar-based composites, that have enhanced capabilities as adsorbents for removing As from water and soils. Biochar-based materials such as $\mathrm{ZnCl}_{2}$-activated biochar and $\mathrm{Ca}-/ \mathrm{Fe}$-modified biochar were used to remove $\mathrm{As}$ (including As(III) and As(V)) in water (Samsuri et al., 2013; Xia et al., 2016). However, the preparation procedures for these materials are relatively complex and expensive.

Biochar has a porous structure that can be used to support the distribution of particles within its matrix (Wang et al., 2015a). Red mud shows some potential for As adsorption due to its distinctive oxide-rich constitution, especially iron and aluminum oxides, surface hydroxyl groups and its porous nature (Altundogan et al., 2000; Liu et al., 2011). Both rice straw and red mud are low cost, abundant materials. However, there seems to be a lack of information on the use of biochar for As remediation, when compared with other metals (Beesley et al., 2014). Based on this evidence, the study attempts to develop a novel red mud-modified biochar, in order to (1) characterize its physicochemical properties; (2) compare the kinetics of As sorption by red mud-modified biochar and untreated biochar produced from rice straw; and (3) investigate adsorption mechanisms using X-ray absorption spectroscopy (XANES).

(1)




\section{Materials and methods}

114

115

116

117

\subsection{Materials}

All chemicals used in this study were analytical grade. Deionized water was used to prepare all solutions. Sodium arsenite $\left(\mathrm{NaAsO}_{2}\right)$ and sodium arsenate $\left(\mathrm{Na}_{2} \mathrm{HAsO}_{4} \cdot 12 \mathrm{H}_{2} \mathrm{O}\right)$ were purchased from Aldrich Chemical Co.

Rice straw was collected from a paddy field located around Central South University (Hunan, P.R. China). It was milled into a powder $(0.15 \mathrm{~mm})$ then used for biochar production (Chang et al., 2014). Red mud (RM), obtained from the Guangxi Pingguo alumina refinery (Pingguo, Guangxi Province, China), was oven-dried overnight at $60{ }^{\circ} \mathrm{C}$.

\subsection{Biochar preparation}

Red mud-modified biochar (RM-BC) was produced using the method adopted by Wang et al. (2015a) and Yao et al. (2014). Approximately $2 \mathrm{~g}$ of RM at its natural $\mathrm{pH}$ was added to $500 \mathrm{~mL}$ deionized water and stirred for $30 \mathrm{~min}$ with a Magnetic Stirrer (85-2, Zhongda instrument corporaion in Jintan) to obtain stable RM suspensions.

Subsequently, $10 \mathrm{~g}$ of rice straw was thoroughly mixed with the RM suspension and the mixture stirred for $2 \mathrm{~h}$. Finally, the RM-modified feedstock was separated from the liquid by oven-drying at $80^{\circ} \mathrm{C}$.

Pyrolysis of the RM-modified feedstock took place in a muffle furnace $\left(\mathrm{SX}_{2}-5-12\right.$, 
Yuandong Therm corporaion in Changsha, China) at $600{ }^{\circ} \mathrm{C}$. In order to keep an oxygen-free atmosphere during the pyrolysis process, oxygen-free $\mathrm{N}_{2}$ was circulated into the system at a flowrate of $200 \mathrm{~mL} / \mathrm{min}$. The temperature increased at a rate of $5{ }^{\circ} \mathrm{C} / \mathrm{min}$ until $600^{\circ} \mathrm{C}$. The samples were pyrolyzed in the muffle furnace for $6 \mathrm{~h}$. All biochars were cooled to room temperature $\left(25{ }^{\circ} \mathrm{C}\right)$, washed with deionized water several times to remove foreign substances, and oven dried at $80{ }^{\circ} \mathrm{C}$. Rice straw without RM modification was prepared by the same process. Hereafter, red mud-modified biochar and untreated biochar are named RM-BC and BC respectively.

\subsection{Material characterization}

The surface areas of $\mathrm{BC}$ and $\mathrm{RM}-\mathrm{BC}$ were obtained using $\mathrm{N}_{2}$ sorption on a Monosorb surface area analyzer and calculated using the Brunauer-Emmett-Teller (BET) method. Surface morphology of the each biochar was examined using a scanning electron microscope, equipped with energy dispersive X-ray spectroscopy (SEM, Phenom XL). Furthermore, the crystal structure of these materials was characterized by X-ray powder diffraction (XRD, D/max $2550 \mathrm{VB}+\mathrm{X})$.

\subsection{The effects of solution $\mathrm{pH}$ on adsorption}

Two stock solutions of $1000 \mathrm{mg} / \mathrm{L} \mathrm{As(III)}$ and As(V) were prepared by dissolving $\mathrm{NaAsO}_{2}$ and $\mathrm{Na}_{2} \mathrm{HAsO}_{4} \cdot 12 \mathrm{H}_{2} \mathrm{O}$ in deionized water, respectively. Working solutions (10 mg/L As(V) and 10mg/L As(III)) were prepared by diluting stock solutions with deionized water. The working solutions contained $0.01 \mathrm{M} \mathrm{NaCl}$ to maintain a constant 
155

156

157

ionic strength. $\mathrm{pH}$ was adjusted to $2,4,6,8,10$ and 12 respectively, using $0.1 \mathrm{~mol} \cdot \mathrm{L}^{-1}$ $\mathrm{HCl} / \mathrm{NaOH}$. Approximately $0.12 \mathrm{~g}$ of $\mathrm{BC}$ or $\mathrm{RM}-\mathrm{BC}$ was added to $30 \mathrm{~mL}$ $\mathrm{As}(\mathrm{V}) / \mathrm{As}(\mathrm{III})$ working solutions of the different $\mathrm{pH}$ values to make $4 \mathrm{~g} \cdot \mathrm{L}^{-1}$ concentrations. Subsequently these samples were shaken at a constant temperature (25 $\pm 1{ }^{\circ} \mathrm{C}$ ) in an oscillator bath (DDHZ-300, Experimental facility corporation in TaiCang) at $200 \mathrm{rpm} / \mathrm{min}$ for $24 \mathrm{~h}$. Samples were then immediately passed through syringe membrane filters $(0.45 \mathrm{~mm})$ to determine As concentrations. Total As in the filtrate was measured by hydride generation atomic fluorescence spectrometry (HG-AFS, AFS-8230). The adsorbed concentration $\mathrm{q}\left(\mu \mathrm{g} \mathrm{g}^{-1}\right)$ of arsenate and arsenite was estimated as follows (Zhang et al., 2016):

$$
\mathrm{q}=\frac{\left(\mathrm{C}_{0}-\mathrm{C}_{\mathrm{t}}\right) \mathrm{V}}{\mathrm{m}}
$$

Where $\mathrm{q}\left(\mu \mathrm{g} \mathrm{g}^{-1}\right)$ is the concentration of $\mathrm{As}(\mathrm{V}) / \mathrm{As}(\mathrm{III})$ adsorbed at equilibrium; $\mathrm{C}_{0}$ and $\mathrm{C}_{\mathrm{t}}\left(\mu \mathrm{g} \mathrm{L}^{-1}\right)$ are the initial and equilibrium solute concentrations individually; $\mathrm{V}$ (L) is the solute volume and $\mathrm{m}(\mathrm{g})$ is the adsorbents mass.

\subsection{Adsorption kinetics}

Prior to the study, it was observed that adsorption of $\mathrm{As}(\mathrm{V})$ and $\mathrm{As}(\mathrm{III})$ was most effective between 6 to 10 on $\mathrm{BC}$ and 2 to 10 on RM-BC. To investigate As adsorption mechanisms, adsorption kinetic studies were carried out at room temperature $(25 \pm$ $\left.1^{\circ} \mathrm{C}\right)$. Approximately $0.12 \mathrm{~g}\left(4 \mathrm{~g} \cdot \mathrm{L}^{-1}\right)$ of $\mathrm{BC}$ and $\mathrm{RM}-\mathrm{BC}$ were added to $30 \mathrm{~mL}$ of $\mathrm{As}(\mathrm{V}) / \mathrm{As}(\mathrm{III})$ solutions (with concentrations of $10 \mathrm{mg} \cdot \mathrm{L}^{-1}$ ). The solutions were then shaken at $200 \mathrm{rpm}$ at optimal $\mathrm{pH}$ for predetermined time intervals of $0.5,1,2,4,8,12$, 
17716 and $24 \mathrm{~h}$ respectively. Samples were removed from the shaker and the adsorbents 178 immediately separated from the solution by filtration. Total As in the filtrate was 179 determined by HG-AFS (AFS-8230, Beijing Jitian Instruments Co., China). All 180 investigations were performed in triplicate.

181 Kinetics data for As(V) and As(III) were fitted with a pseudo-first-order model, 182 pseudo-second-order kinetic model and the Elovich model to explain the adsorption process. The governing equations of the mathematical models are listed as follows:

$$
\text { pseudo-first-order: } \quad \frac{\mathrm{dq} t}{\mathrm{dt}}=\mathrm{k}_{1}\left(\mathrm{q}_{\mathrm{e}}-\mathrm{q}_{\mathrm{t}}\right)
$$

$$
\text { pseudo-second-order: } \quad \frac{\mathrm{dq} t}{\mathrm{dt}}=\mathrm{k}_{2}\left(\mathrm{q}_{\mathrm{e}}-\mathrm{q}_{\mathrm{t}}\right)^{2}
$$

186 Elovich:

$$
\frac{d q_{t}}{d t}=\alpha \exp \left(-\beta q_{t}\right)
$$

Where $\mathrm{q}_{\mathrm{t}}$ and $\mathrm{q}_{\mathrm{e}}(\mu \mathrm{g} / \mathrm{g})$ are the concentrations of As adsorbed at $\mathrm{t}$ and equilibrium time respectively, and $\mathrm{k}_{1}\left(\mathrm{~h}^{-1}\right), \mathrm{k}_{2}\left(\mathrm{~g} \mu \mathrm{g}^{-1} \mathrm{~h}^{-1}\right)$ and $\mathrm{k}_{\mathrm{d}}\left(\mu \mathrm{g} \mathrm{g}^{-1} \min ^{-1 / 2}\right)$ are the rate constants for the pseudo-first-order kinetic model, pseudo-second-order kinetic model and intraparticle diffusion respectively. $\mathrm{C}\left(\mu \mathrm{g} \mathrm{g}^{-1}\right)$ is the $\mathrm{y}$-intercept. Initial adsorption rate is regarded as $\alpha\left(\mu \mathrm{g} \mathrm{g}^{-1}\right)$ and $\beta\left(\mu \mathrm{g} \mathrm{g}^{-1}\right)$ the desorption constant. measured at different initial As(V)/As(III) concentrations (1-50 mg/L). Equilibrium adsorption investigations were performed for $24 \mathrm{~h}$ at optimal $\mathrm{pH}$. Two adsorption isothermal models, Langmuir and Freundlich, were applied to describe adsorption 
isotherms. Equations were expressed as follows:

$$
\text { Langmuir: } \quad \mathrm{q}_{\mathrm{e}}=\frac{\mathrm{q}_{\mathrm{m}} \mathrm{k}_{\mathrm{L}} \mathrm{C}_{\mathrm{e}}}{1+\mathrm{K}_{\mathrm{L}} \mathrm{C}_{\mathrm{e}}}
$$

$$
\text { Freundlich: } \quad \mathrm{q}_{\mathrm{e}}=\mathrm{K}_{\mathrm{F}} \mathrm{C}_{\mathrm{e}}{ }^{\mathrm{n}}
$$

Where $\mathrm{q}_{\mathrm{e}}\left(\mu \mathrm{g} \cdot \mathrm{g}^{-1}\right)$ is the adsorbed concentration of As at equilibrium; $\mathrm{C}_{\mathrm{e}}\left(\mathrm{mg} \cdot \mathrm{L}^{-1}\right)$ is the equilibrium concentration of As; $\mathrm{q}_{\mathrm{m}}\left(\mu \mathrm{g} \cdot \mathrm{g}^{-1}\right)$ denotes the maximum adsorption capacity and $\mathrm{n}$ is the heterogeneity parameter; $\mathrm{K}_{\mathrm{L}}\left(\mathrm{L} \cdot \mathrm{mg}^{-1}\right)$ and $\mathrm{K}_{\mathrm{F}}$ represent the constants of Langmuir and Freundlich respectively.

For the Langmuir model, equilibrium parameter $\left(R_{L}\right)$, employed to determine whether adsorption is favorable or not, is as follows (Sun et al., 2015):

$$
\mathrm{R}_{\mathrm{L}}=\frac{1}{1+\mathrm{K}_{\mathrm{L}} \mathrm{C}_{0}}
$$

Where $\mathrm{C}_{0}\left(\mathrm{mg} \mathrm{L}^{-1}\right)$ is the initial concentration of As and $\mathrm{K}_{\mathrm{L}}\left(\mathrm{L} \mathrm{mg}^{-1}\right)$ is the Langmuir constant. The adsorption process is either unfavorable $\left(R_{L}>1\right)$, linear $\left(R_{L}=\right.$ $1)$, favorable $\left(0<R_{L}<1\right)$ or irreversible $\left(R_{L}=0\right)$.

\subsection{X-ray absorption spectroscopy analysis}

The mechanism of As(V) sorption on RM-BC was investigated by X-ray absorption spectroscopy (XANES). For reference XANES spectra, all minerals (hematite, goethite, magnetite and gibbsite) were purchased from Sigma. Approximately $4 \mathrm{~g} \cdot \mathrm{L}^{-1}$ of each mineral was applied to $30 \mathrm{~mL}$ of $\mathrm{As}(\mathrm{V})$ solution $\left(10 \mathrm{mg} \cdot \mathrm{L}^{-1}\right)$ for $24 \mathrm{~h}$ using $0.01 \mathrm{~mol} \cdot \mathrm{L}^{-1} \mathrm{NaCl}$ to maintain ionic strength. After sorption, the suspension was centrifuged, washed twice with $0.01 \mathrm{~mol} \cdot \mathrm{L}^{-1} \mathrm{NaCl}$ at $\mathrm{pH} 5.5$, then washed with Ultrapure Water and subsequently freeze-dried (Fan et al., 2014). 
The synchrotron was operated at $3.5 \mathrm{GeV}$ and beam current around $150-210 \mathrm{~mA}$

227 determine As species.

\subsection{Data Analysis}

All data was analyzed in SPSS 23.0. Figures were created in Origin 9.0.

\section{Results and discussion}

\subsection{Characterization}


compared to that of BC (Fig. 1b). The surface of RM-BC appeared smooth without adsorption (Fig. 1b) and then became coarser after the adsorption of As(V) (Fig. 1c) and As(III) (Fig. 1d). The EDS spectra analysis showed that As was coated on the surface of the RM-BC, demonstrating that adsorption had occurred (Fig. 1c and 1d).

The structures of RM-BC and BC were clearly different, when examined by X-ray powder diffraction (XRD). XRD analysis of the RM-BC revealed the presence of crystalline phases identified as hematite, magnetite, goethite, calcite, gibbsite and perovskite which were not detected in the crystalline phases of BC (Fig. 2). The results further confirmed that red mud had been successfully loaded on the surfaces of the biochar matrix.

\subsection{Effect of $p H$}

The effect of $\mathrm{pH}$ on $\mathrm{As}(\mathrm{V})$ and $\mathrm{As}(\mathrm{III})$ adsorbed by $\mathrm{BC}$ and $\mathrm{RM}-\mathrm{BC}$ are presented in Fig.3.a and Fig.3.b, respectively. The amount of adsorbed $\mathrm{As}(\mathrm{V})\left(\mathrm{q}, \mu \mathrm{g} \cdot \mathrm{g}^{-1}\right)$ decreased with increasing pH on RM-BC (Fig.3.a). The maximum adsorption density for $\mathrm{As}(\mathrm{V})$ at $\mathrm{pH}=2$ was $1622.51 \mu \mathrm{g} \cdot \mathrm{g}^{-1}$. Adsorption capacity of $\mathrm{BC}$ for $\mathrm{As}(\mathrm{V})$ increased with increasing $\mathrm{pH}$ from 2 to 6 , but then decreased when the $\mathrm{pH}$ ranged from 6 to 12. The maximum adsorption of $\mathrm{BC}$ was $\mathrm{q}=481.61 \mu \mathrm{g} \cdot \mathrm{g}^{-1}$ at $\mathrm{pH}=6$. Biochar had a somewhat lower $\mathrm{As}(\mathrm{V})$ adsorption capacity, when compared to that of RM-BC. The effects of $\mathrm{pH}$ on $\mathrm{As}(\mathrm{III})$ adsorption are presented in Fig.3.b. Clearly, BC and RM-BC showed similar trends on the $\mathrm{pH}$-dependent adsorption curves. The quantity adsorbed increased with $\mathrm{pH}$, increasing from 2 to 10 , but when $\mathrm{pH}$ was elevated from 
10 to 12 , the adsorbed amount of both absorbents decreased. Overall, the results indicated that $\mathrm{As}(\mathrm{V})$ is adsorbed in acidic $\mathrm{pH}$ conditions, whilst $\mathrm{As}(\mathrm{III})$ tends to be adsorbed in alkaline environments. In addition, red mud modification significantly enhanced the sorption ability of biochar both on As(V) and As(III).

$\mathrm{pH}$ is considered as a crucial factor influencing As species distribution and the surface charge of BC/RM-BC. Anionic species of arseneous and arsenic acids are dictated by $\mathrm{pH}$. Ionization equations are listed as follows (Wei et al., 2016):

$$
\begin{array}{lc}
\mathrm{H}_{3} \mathrm{AsO}_{3} \leftrightarrow \mathrm{H}_{2} \mathrm{AsO}_{3}{ }^{-}+\mathrm{H}^{+} & \mathrm{pKa}_{1}=9.23 \\
\mathrm{H}_{2} \mathrm{AsO}_{3}{ }^{-} \leftrightarrow \mathrm{HAsO}_{3}{ }^{2-}+\mathrm{H}^{+} & \mathrm{pKa}_{2}=12.10 \\
\mathrm{HAsO}_{3}{ }^{2-} \leftrightarrow \mathrm{AsO}_{3}{ }^{3-}+\mathrm{H}^{+} & \mathrm{pKa}_{3}=13.41 \\
\mathrm{H}_{3} \mathrm{AsO}_{4} \leftrightarrow \mathrm{H}_{2} \mathrm{AsO}_{4}{ }^{-}+\mathrm{H}^{+} & \mathrm{pKa}_{1}=2.24 \\
\mathrm{H}_{2} \mathrm{AsO}_{4}{ }^{-} \leftrightarrow \mathrm{HAsO}_{4}{ }^{2-}+\mathrm{H}^{+} & \mathrm{pKa}_{2}=6.94 \\
\mathrm{HAsO}_{4}{ }^{2-} \leftrightarrow \mathrm{AsO}_{4}{ }^{3-}+\mathrm{H}^{+} & \mathrm{pKa}_{3}=11.50
\end{array}
$$

When $\mathrm{pH}$ is below the point of zero charge ( $\mathrm{pH}$ PzC), the surface of adsorbents will form positive charges. At this time, $\mathrm{As}(\mathrm{V})$ predominantly exists as $\mathrm{H}_{2} \mathrm{AsO}_{4}{ }^{-}$and adsorption occurs by electrostatic and chemical attraction (Cheng et al., 2016). At higher $\mathrm{pH}$ values, the major As species exist as $\mathrm{HAsO}_{4}{ }^{2-}$ and $\mathrm{AsO}_{4}{ }^{3-}$. However, the availability of binding sites declines with increasing $\mathrm{pH}$. When the $\mathrm{pH}$ is above the $\mathrm{pH}_{\mathrm{PZC}}$ adsorbent surfaces develop negative charges, which repulse anions including $\mathrm{HAsO}_{4}{ }^{2-}$ and $\mathrm{AsO}_{4}{ }^{3-}$. In the meantime, hydroxide ions compete for positively charged surface sites, and as a result weaken the adsorption process (Feng et al., 2015). Furthermore, an early study reported that the properties and mineralogical 
composition of RM will be changed by $\mathrm{pH}$ and specific sorption locations of RM will decrease with increasing pH (Castaldi et al., 2010).

The adsorbed volume of As(III) reached its maximum between pH 8 to 10 (Fig.3.b).

This is consistent with the results obtained by Baig et al. (2014), using magnetic biochar, who noted that $\mathrm{As}(\mathrm{III})$ adsorption reached a maximum at $\mathrm{pH}=8$ (Baig et al., 2014). Manju et al. (1998) using copper impregnated activated carbon as a sorbent, also discovered that As(III) adsorption increased with increasing $\mathrm{pH}$ (Manju et al., 1998). However, Yu et al. (2015) demonstrated that As(III) reached a maximum at $\mathrm{pH}=3$ with manganese oxide-modified biochar (Yu et al., 2015). This variation may be the result of the diverse adsorbents used in the investigations.

\subsection{Adsorption Kinetics}

$\mathrm{As}(\mathrm{V})$ and As(III) kinetic experiments revealed a rapid initial sorption followed by a smooth increase, reaching equilibrium within less than $24 \mathrm{~h}$ (Fig. 4). First-order and second-order models were used to describe mononuclear and binuclear adsorption, whilst the Elovich model considers the influence of desorption (Lü et al., 2013). Compared with BC, RM-BC showed a greater sorption capacity for As. Kinetic models and best-fit parameter values for $\mathrm{As}(\mathrm{V})$ and $\mathrm{As}(\mathrm{III})$ adsorption data are listed in Table 1. The pseudo-second-order model fits the kinetic data well when compared to pseudo-first-order for $\mathrm{As}(\mathrm{V})$ adsorption on all adsorbents (Table 1). However, for As(III) adsorption on BC and RM-BC, the fit is different. Between the three kinetic models, the former is more in favor of the pseudo-second-order model. 
For the latter, the Elovich model agrees with the data more accurately.

The results revealed that: (1) according to the assumptions of the pseudo-second-order kinetic model, the reaction rate is relative to the amount of $\mathrm{BC} / \mathrm{RM}-\mathrm{BC}$ surface active sites and the rate-limiting step will possibly be chemical sorption (Taty-Costodes et al., 2003; Mohan et al., 2011), (2) the adsorption of As(III) on RM-BC was a heterogeneous process and may be controlled by multiple mechanisms including chemisorption (Yao et al., 2014), and (3) both BC and RM-BC removed $\mathrm{As}(\mathrm{V})$ more effectively than $\mathrm{As}(\mathrm{III})$. In addition, the adsorption density of $\mathrm{As}(\mathrm{V})$ on $\mathrm{RM}-\mathrm{BC}$ is more than that of $\mathrm{BC}$.

\subsection{Adsorption isotherms}

Langmuir and Freundlich isotherms for $\mathrm{As}(\mathrm{V})$ and $\mathrm{As}(\mathrm{III})$ on $\mathrm{BC}$ and $\mathrm{RM}-\mathrm{BC}$ are displayed in Fig. 5. With increasing As concentration, As adsorption increased greatly until reaching equilibrium. In this study, all sorption isotherms were "L" shaped with higher $\mathrm{R}^{2}$ compared to the Freundlich model (Table 2). The calculated Langmuir maximum adsorption capacity $\left(\mathrm{Q}_{\max }\right)$ of $\mathrm{RM}-\mathrm{BC}$ for $\mathrm{As}(\mathrm{V})$ and $\mathrm{As}(\mathrm{III})$ were 5923.8 and $520.0 \mathrm{ug} \cdot \mathrm{g}^{-1}$ respectively. In contrast, the $\mathrm{Q}_{\max }$ of $\mathrm{BC}$ for $\mathrm{As}(\mathrm{V})$ and $\mathrm{As}(\mathrm{III})$ were only $552.0 \mathrm{ug} \cdot \mathrm{g}^{-1}$ and $447.6 \mathrm{ug} \cdot \mathrm{g}^{-1}$ respectively.

The Langmuir isotherm is used to describe monolayer adsorption on sorbent surfaces (Awwad et al., 2010). Both BC and RM-BC obey the adsorption mechanisms of Langmuir, which is in accordance with many carbonaceous adsorbents (Zhang et al., 2013; Wang et al., 2015a). Red mud-modified biochar exhibited improved 
removal for $\mathrm{As}(\mathrm{V})$ and $\mathrm{As}(\mathrm{III})$ compared to $\mathrm{BC}$, suggesting that it may enhance biochar adsorption sites ( Wang et al., 2015a; Li et al., 2016).

In this work, $\mathrm{R}_{\mathrm{L}}$ values for $\mathrm{As}(\mathrm{V})$ adsorption on $\mathrm{BC}$ and $\mathrm{RM}-\mathrm{BC}$ and $\mathrm{As}(\mathrm{III})$ adsorption on $\mathrm{BC}$ and $\mathrm{RM}-\mathrm{BC}$ were in the range of $0.0663-0.825,0.303-0.970$, 0.136-0.919, 0.0778-0.860 respectively, indicating that adsorption was favorable.

Table 4 presents a comparison of maximum adsorptive capacities for various As(V) adsorbents. The Langmuir maximum sorption capacity of RM-BC for $\mathrm{As}(\mathrm{V})$ is lower than that of Fe coated biochars (Samsuri et al.(2013)) and La loaded biochar (Feng et al. (2015)). Nevertheless, production of biochar treated with pure chemical reagents (Fe and La) would be expensive at an industrial level.

\subsection{Analysis of adsorption mechanisms}

K-edge XANES analyses for As standards and RM-BC-As(V) are presented in Fig. 6. The excitation energies are displayed at $11872.4 \mathrm{eV}$ and $11876.5 \mathrm{eV}$ corresponding to $\mathrm{As}(\mathrm{III})$ and $\mathrm{As}(\mathrm{V})$ respectively. The results of XANES spectra revealed that both $\mathrm{As}(\mathrm{V})$ and $\mathrm{As}(\mathrm{III})$ were adsorbed on the surface of the red mud. Arsenate was the major species and accounted for $97.6 \%$ of the total As (Table 3). In addition, LCF results revealed three main As phases on RM-BC including hematite-As(V) (53.5\%), magnetite-As(V) (33.8\%), and gibbsite-As(V) (13.6\%), which probably formed during the sorption process (Table 3).

Previous studies demonstrated that iron and alumina oxides play a key role in As sorption (Zhang et al., 2014; Wang et al., 2015a). The presence of hematite, goethite, magnetite and gibbsite, as revealed by $\mathrm{XRD}$, on $\mathrm{RM}-\mathrm{BC}$ is consistent with that 
353

354

355

356

357

358

359

360

361

362

363

364

365

366

367

368

369

370

371

372

373

374

reported in other studies (Li et al., 2009; Liu and Naidu, 2014). Arsenate forms inner sphere bidentate binuclear complexes on gibbsite (Ladeira et al., 2001). Hematite, goethite, and magnetite both effectively remove $\mathrm{As}(\mathrm{III})$ and $\mathrm{As}(\mathrm{V})$ from solutions, especially hematite, as this demonstrated the greatest adsorption capacity in acidic $\mathrm{pH}$ conditions (Gimenez et al., 2007; Mamindy-Pajany et al., 2011). Arsenate was strongly bound to iron oxides by forming inner sphere complexes through ligand exchange (Jain et al., 1999; Mamindy-Pajany et al., 2011).

According to XANES results, possible adsorption mechanisms for $\mathrm{As}(\mathrm{V})$ on RM-BC are presented in Fig.7. The structure M-O-As(V) formed may substantially enhanced the adsorption capacity of $\mathrm{As}(\mathrm{V})$. This figure was consistent with previous studies demonstrating that the mechanisms responsible for As adsorption on biochar are through electrostatic interactions, surface complexation through ligand exchange (described as inner-sphere surface monodentate and bidentate complexes), and chemical interactions between As and surface functional groups (Li et al., 2016; Wang et al., 2015a; Zhang et al., 2013).

\section{Conclusion}

Red mud and rice straw biochar are promising materials for As contaminated soil remediation due to their improved adsorbent capacity. RM-BC revealed improved removal of both $\mathrm{As}(\mathrm{V})$ and $\mathrm{As}(\mathrm{III})$, with the maximum adsorption capacity ten times greater than that of the untreated biochar. All sorption isotherms produced improved fits for the Langmuir model. X-ray absorption near-edge spectroscopy indicated that the adsorption of $\mathrm{As}(\mathrm{V})$ on $\mathrm{RM}-\mathrm{BC}$ was possibly due to surface complexation and 
electrostatic interactions.

\section{Acknowledgments}

Financial supports from China Postdoctoral Science Foundation (2016M590755), Natural Science Foundation of Hunan, China (No. 2015JJ3142) and Teacher's Research Foundation of Central South University are gratefully acknowledged. The authors would also like to thank the Shanghai Synchrotron Radiation Facility for technical assistance, and Mr. Wangyang Zhou and Mr. Jing Yu Mo in Central South University for assisting various experiments and preparation of the manuscript.

\section{References}

Adra, A., Morin, G., Nguema, G.O., Brest, J., 2015. Arsenate and Arsenite Adsorption onto Al-containing ferrihydrites implications for arsenic immobilization after neutralization of acid mine drainage. Appl. Geochem. 64, 2-9.

Ahmad, M., Rajapaksha, A.U., Lim, J.E., Zhang, M., Bolan, N., Mohan, D., Vithanage, M., Lee, S.S., Ok, Y.S., 2014. Biochar as a sorbent for contaminant management in soil and water: A review. Chemosphere. 99, 19-33.

Altundogan, H.S., Altundogan, S., Tumen, F., Bildik, M., 2000. Arsenic removal from aqueous solutions by adsorption on red mud, Waste Manage. 20, 761-767.

Awwad, N.S., Gad, H.M.H., Ahmad, M.I., Aly, H.F., 2010. Sorption of lanthanum and erbium from aqueous solution by activated carbon prepared from rice husk. Colloids Surf., B. 81, 593-599.

Baig, S.A., Zhu, J., Muhammad, N., Sheng, T., Xu, X., 2014. Effect of synthesis methods on magnetic Kans grass biochar for enhanced As(III, V) adsorption from aqueous solutions. Biomass Bioenergy. 71, 299-310.

Beesley, L., Inneh, O.S., Norton, G.J., Moreno-Jimenez, E., Pardo, T., Clemente, R., Dawson, J.J.C., 2014. Assessing the influence of compost and biochar amendments on the mobility and toxicity of metals and arsenic in a naturally contaminated mine soil. Environ. Pollut. 186, 195-202.

Castaldi, P., Silvetti, M., Enzo, S., Melis, P., 2010. Study of sorption processes and FT-IR analysis of arsenate sorbed onto red muds (a bauxite ore processing waste). J. Hazard. Mater. 175, 172-178. Chang, K., Chen, C., Lin, J., Hsien, J., Wang, Y., Zhao, F., Shih, Y., Xing, Z., Chen, S., 2014. Rice straw-derived activated carbons for the removal of carbofuran from an aqueous solution. New Carbon Mater. 29, 47-54.

Cheng, Q., Huang, Q., Khan, S., Liu, Y., Liao, Z., Li, G., Ok, Y.S., 2016. Adsorption of Cd by peanut 
husks and peanut husk biochar from aqueous solutions. Ecol. Eng. 87, 240-245.

Fan, J.X., Wang, Y., Liu, C., Wang, L., Yang, K., Zhou, D., Li, W., Sparks, D.L., 2014. Effect of iron oxide reductive dissolution on the transformation and immobilization of arsenic in soils: New insights from X-ray photoelectron and X-ray absorption spectroscopy. J. Hazard. Mater. 279, 212-219.

Feng, Y., Xue, L., Yang, B., Liu, Y., Duan, J., He, S., Yang, L., 2015. Adsorption of As from aqueous solution by lanthanum oxide-loaded biochar: process and mechanisms. Journal of Agro-Environment Science. 34, 2190-2197.

Genc, H., Tjell, J.C., Mcconchie, D., Schuiling, O., 2003. Adsorption of arsenate from water using neutralized red mud, J. Colloid Interface Sci. 264, 327-334.

Gimenez, J., Martinez, M., Depabio, J., Rovira, M., Duro, L., 2007. Arsenic sorption onto natural hematite, magnetite, and goethite. J. Hazard. Mater. 141, 575-580.

Gregory, S.J., Anderson, C.W.N., Camps Arbestain, M., McManus, M.T., 2014. Response of plant and soil microbes to biochar amendment of an arsenic-contaminated soil. Agriculture, Ecosystems \& Environment. 191, 133-141.

Guo, H., Li, Y., Zhao, K., Ren, Y., Wei, C., 2011. Removal of arsenite from water by synthetic siderite: Behaviors and mechanisms. J. Hazard. Mater. 186, 1847-1854.

Hartley, W., Dickinson, N.M., Riby, P., Lepp, N.W., 2009. Arsenic mobility in brownfield soils amended with green waste compost or biochar and planted with Miscanthus. Environ. Pollut. 157, 2654-2662.

Jadhav, S.V., Bringas, E., Yadav, G.D., Rathod, V.K., Ortiz, I., Marathe, K.V., 2015. Arsenic and fluoride contaminated groundwaters: A review of current technologies for contaminants removal. J. Environ. Manage. 162, 306-325.

Jain, A., Raven, K.P., Loeppert, R.H., 1999. Arsenite and arsenate adsorption on ferrihydrite: surface charge reduction and net $\mathrm{OH}^{-}$release stoichiometry. Environ. Sci. Technol. 33, 1179-1184.

Kim, E.J., Yoo, J., Baek, K., 2014. Arsenic speciation and bioaccessibility in arsenic-contaminated soils: sequential extraction and mineralogical investigation. Environ. Pollut. 186, 29-35.

Klauber, C., Gräfe, M., Power, G., 2011. Bauxite residue issues: II. options for residue utilization. Hydrometallurgy. 108, 11-32.

Ladeira, A.C.Q., Ciminelli, V.S.T., Duarte, H.A., Alves, M.C.M., Ramos, A.Y., 2001. Mechanism of anion retention from EXAFS and density functional calculations: Arsenic (V) adsorbed on gibbsite, Geochimica Et Cosmochimica Acta. 8, 1211-1217.

Lee, S., Kim, E.Y., Park, H., Yun, J., Kim, J., 2011. In situ stabilization of arsenic and metal-contaminated agricultural soil using industrial by-products. Geoderma. 161, 1-7.

Li, R., Wang, J.J., Zhou, B., Awasthi, M.K., Ali, A., Zhang, Z., Gaston, L.A., Lahori, A.H., Mahar, A., 2016. Enhancing phosphate adsorption by $\mathrm{Mg} / \mathrm{Al}$ layered double hydroxide functionalized biochar with different $\mathrm{Mg} / \mathrm{Al}$ ratios. Sci. Total Environ. 559, 121-129.

Li, X., Xiao, W., Liu, W., Liu, G., Peng, Z., Zhou, Q., Qi, T., 2009. Recovery of alumina and ferric oxide from Bayer red mud rich in iron by reduction sintering. Trans. Nonferrous Met. Soc. 19, 1342-1347.

Liu, Y., Naidu, R., 2014. Hidden values in bauxite residue (red mud): recovery of metals. Waste Manage. 34, 2662-2673.

Liu, Y., Naidu, R., Ming, H., 2011. Red mud as an amendment for pollutants in solid and liquid phases. Geoderma. 163, 1-12.

Lone, A.H., Najar, G.R., Ganie, M.A., Sofi, J.A., Ali, T., 2015. Biochar for sustainable soil health: a 
review of prospects and concerns, Pedosphere. 25, 639-653.

Lopes, G., Guilherme, L.R.G., Costa, E.T.S., Curi, N., Penha, H.G.V., 2013. Increasing arsenic sorption on red mud by phosphogypsum addition. J. Hazard. Mater. 262, 1196-1203.

Lü̆, J., Liu, H., Liu, R., Zhao, X., Sun, L., Qu, J., 2013. Adsorptive removal of phosphate by a nanostructured $\mathrm{Fe}-\mathrm{Al}-\mathrm{Mn}$ trimetal oxide adsorbent. Powder Technol. 233, 146-154.

Mamindy-Pajany, Y., Hurel, C., Marmier, N., Roméo, M., 2011. Arsenic (V) adsorption from aqueous solution onto goethite, hematite, magnetite and zero-valent iron: Effects of $\mathrm{pH}$, concentration and reversibility. Desalination. 281, 93-99.

Manju, G.N., Raji, C., Anirudhan T.S., 1998. Evaluation of coconut husk carbon for the removal of arsenic from water. Water Res. 32, 3062-3070.

Mohan, D., Rajput, S., Singh, V.K., Steele, P.H., Pittman, C.U., 2011. Modeling and evaluation of chromium remediation from water using low cost bio-char, a green adsorbent. J. Hazard. Mater. 188, 319-333.

Rubinos D. A., Arias M., Díaz-Fierros F., Barral1 M. T., 2005. Speciation of adsorbed arsenic(V) on red mud using a sequential extraction procedure. Mineralogical Magazine, 69 (5), 591-600.

Samsuri, A.W., Sadegh-Zadeh, F., Seh-Bardan, B.J., 2013. Adsorption of As(III) and As(V) by Fe coated biochars and biochars produced from empty fruit bunch and rice husk. Journal of Environmental Chemical Engineering, 1, 981-988.

Sun, L., Chen, D., Wan, S., Yu, Z., 2015. Performance, kinetics, and equilibrium of methylene blue adsorption on biochar derived from eucalyptus saw dust modified with citric, tartaric, and acetic acids. Bioresource. Technol. 198, 300-308.

Tan, X., Liu, Y., Gu, Y., Xu, Y., Zeng, G., Hu, X., Liu, S., Wang, X., Liu, S., Li, J., 2016. Biochar-based nano-composites for the decontamination of wastewater: a review. Bioresource. Technol. 212, 318-333.

Taty-Costodes, V.C., Fauduet, H., Porte, C., Delacroix, A., 2003. Removal of Cd(II) and Pb(II) ions, from aqueous solutions by adsorption onto sawdust of Pinus sylvestris. J. Hazard. Mater. 105, 121-142. Wang, S., Gao, B., Zimmerman, A.R., Li, Y., Ma, L., Harris, W.G., Migliaccio, K.W., 2015a. Removal of arsenic by magnetic biochar prepared from pinewood and natural hematite. Bioresource. Technol. 175, 391-395.

Wang, S., Gao, B., Li, Y., Mosa, A., Zimmerman, A.R., Mab, L.Q. Harris, W.G., Migliaccio, K.W., 2015b. Manganese oxide-modified biochars: Preparation, characterization, and sorption of arsenate and lead. Bioresource. Technol. 181, 13-17.

Wei, Z., Liang, K., Wu, Y., Zou, Y., Zuo, J., Arriagada, D.C., Pan, Z., Hu, G., 2016. The effect of pH on the adsorption of arsenic(III) and $\operatorname{arsenic}(\mathrm{V})$ at the $\mathrm{TiO}_{2}$ anatase [101] surface. J. Colloid Interface Sci. 462, 252-259.

WHO Arsenic and arsenic compounds. Environmental health criteria 224; World Health Organization: Geneva, Switzerland, 2001

Wu, C., Zou, Q., Xue, S., Pan, W., Huang, L., Hartley, W., Mo, J.Y., Wong, M., 2016a. The effect of silicon on iron plaque formation and arsenic accumulation in rice genotypes with different radial oxygen loss (ROL). Environ. Pollut. 212, 27-33.

Wu, C., Huang, L., Xue, S.G., Qin, Z., Shi, L.Z., 2016b. Review on application of bauxite residue on As comtamination remediation. Environmental Chemistry. 35, 141-149.

Xia, D., Tan, F., Jiang, C.Z, Chen X.Z., Li, H., Zheng, Y., Li, Q., Wang, Y., 2016. ZnCl -activated $^{-}$ biochar from biogas residue facilitates, appl. surf. Sci. 377, 361-369. 
Yan, X.L., Lin, L.Y., Liao, X.Y., Zhang, W.B., Wen, Y., 2013. Arsenic stabilization by zero-valent iron, bauxite residue, and zeolite at a contaminated site planting Panax notoginseng. Chemosphere, 93, 661-667.

Yao, Y., Gao, B., Fang, J., Zhang, M., Chen, H., Zhou, Y., Creamer, A.E., Sun, Y., Yang, L., 2014. Characterization and environmental applications of clay-biochar composites. Chem. Eng. J. 242, 136-143.

Yu Z.H., Huang, Y., Lian, F., Xie, L., LIU, S. Song, Z., 2015. Adsorption of Arsenic (III) on biochar-manganese oxide composites, Journal of Agro-Environment Science. 1, 155-161.

Zhang, M., Gao, B., Varnoosfaderani, S., Hebard, A., Yao, Y., Inyang, M., 2013. Preparation and characterization of a novel magnetic biochar for arsenic removal. Bioresource. Technol. 130, 457-462. Zhang, G., Liu, F., Liu, H., Qu, J., Liu, R., 2014. Respective role of Fe and Mn oxide contents for arsenic sorption in iron and manganese binary oxide: an X-ray absorption spectroscopy investigation. Environ. Sci. Technol. 48, 10316-10322.

Zhang, X., Sarmah, A.K., Bolan, N.S., He, L., Lin, X., Che, L., Tang, C., Wang, H., 2016. Effect of aging process on adsorption of diethyl phthalate in soils amended with bamboo biochar. Chemosphere, $142,28-34$. 
Table 1 Kinetic models and best-fit parameters for As(V) and As(III) adsorption data.

\begin{tabular}{|c|c|c|c|c|c|c|c|c|c|c|c|c|c|}
\hline \multirow[t]{2}{*}{ sample } & & \multicolumn{3}{|c|}{ First-order } & \multicolumn{3}{|l|}{ Second-order } & \multicolumn{3}{|l|}{ Elovich } & \multicolumn{3}{|c|}{ Intraparticle diffusion } \\
\hline & & $\mathrm{k}_{1}\left(\mathrm{~h}^{-1}\right)$ & $\mathrm{q}_{\mathrm{e}}(\mu \mathrm{g} / \mathrm{g})$ & $\mathrm{R}^{2}$ & $\mathrm{k}_{2}\left(\mathrm{~g} \mu \mathrm{g}^{-1} \mathrm{~h}^{-1}\right)$ & $\mathrm{q}_{\mathrm{e}}(\mu \mathrm{g} / \mathrm{g})$ & $\mathrm{R}^{2}$ & $\beta(\mu \mathrm{g} / \mathrm{g})$ & $\alpha(\mu \mathrm{g} / \mathrm{g})$ & $\mathrm{R}^{2}$ & $\mathrm{~K}_{\mathrm{d}}\left(\mu \mathrm{g} \mathrm{g}^{-1} \min ^{-1 / 2}\right)$ & $\mathrm{C}(\mu \mathrm{g} / \mathrm{g})$ & $\mathrm{R}^{2}$ \\
\hline $\mathrm{BC}$ & $\operatorname{As}(V)$ & 1.195 & 451.4 & 0.983 & 0.00357 & 482.9 & 0.987 & 0.0143 & 4168.5 & 0.884 & 62.96 & 233.1 & 0.6664 \\
\hline RM-BC & $\mathrm{As}(\mathrm{V})$ & 1.446 & 1656.5 & 0.900 & 0.00126 & 1758.6 & 0.957 & 0.00435 & 31085.8 & 0.917 & 212.94 & 908.7 & 0.7298 \\
\hline $\mathrm{BC}$ & As(III) & 0.805 & 296.0 & 0.948 & 0.00366 & 319.5 & 0.960 & 0.0190 & 1196.7 & 0.928 & 48.95 & 115.1 & 0.7662 \\
\hline RM-BC & As(III) & 0.686 & 377.9 & 0.911 & 0.00236 & 412.0 & 0.927 & 0.0144 & 1253.1 & 0.962 & 66.57 & 132.9 & 0.8842 \\
\hline
\end{tabular}


530 Table 2 Isotherm models and best-fit parameters for $\mathrm{As}(\mathrm{V})$ and $\mathrm{As}(\mathrm{III})$ adsorption data.

\begin{tabular}{|c|c|c|c|c|c|c|c|}
\hline \multirow[t]{2}{*}{ sample } & & \multicolumn{3}{|c|}{ Langmuir } & \multicolumn{3}{|l|}{ Freundlich } \\
\hline & & $\mathrm{k}\left(\mu \mathrm{g}^{-1}\right)$ & $Q_{\max }(\mu \mathrm{g} / \mathrm{g})$ & $\mathrm{R}^{2}$ & $\mathrm{k}\left(\mu \mathrm{g}^{(1-\mathrm{n})} \mathrm{L}^{\mathrm{n}} \mathrm{g}^{-1}\right)$ & $\mathrm{n}$ & $\mathrm{R}^{2}$ \\
\hline $\mathrm{BC}$ & $\mathrm{As}(\mathrm{V})$ & 0.296 & 552.0 & 0.949 & 179.2 & 0.293 & 0.786 \\
\hline RM-BC & $\mathrm{As}(\mathrm{V})$ & 0.0465 & 5923.8 & 0.997 & 452.9 & 0.579 & 0.985 \\
\hline $\mathrm{BC}$ & As(III) & 0.179 & 447.6 & 0.991 & 119.9 & 0.401 & 0.898 \\
\hline RM-BC & As(III) & 0.333 & 520.0 & 0.995 & 171.2 & 0.312 & 0.911 \\
\hline
\end{tabular}

531

532

533

534

535

536

537

538

539

540

541

542

543

544

545

546

547 
Table 3 SPOIL values of reference materials obtained by target transformation (TT), and linear combination fit (LCF) results of $\mathrm{As}(\mathrm{V})$ adsorption on $\mathrm{RM}-\mathrm{BC}$.

\begin{tabular}{lllll}
\hline \multirow{2}{*}{ References } & \multicolumn{2}{l}{ SPOIL Values } & & LCF results $(\%)$ \\
\cline { 2 - 3 } & Spoil & R & & RM-As $(\mathrm{V})$ \\
\hline As(III) & 0 & 0.01865 & & 2.4 \\
As(V) & 0.3172 & 0.02239 & & 97.6 \\
R-factor & & & 0.00868 \\
Chi-square & & & 0.0697 \\
\hline gibbsite-As(V) & 0 & $9.16 \mathrm{E}-07$ & 13.6 \\
hematite-As(V) & 0 & $1.37 \mathrm{E}-07$ & 53.5 \\
magnetite-As(V) & 1.0423 & $5.61 \mathrm{E}-05$ & \\
R-factor & & & 33.8 \\
Chi-square & & & 0.00241 \\
\hline
\end{tabular}

550

551

552

553

554

555

556

557

558

559

560

561

562

563

564 
Table 4 Comparison of adsorption capabilities for different adsorbents of As(V).

\begin{tabular}{llll}
\hline Adsorbents & Feedstock & $\mathbf{q}_{\max }(\boldsymbol{\mu g} \mathbf{g})$ & References \\
\hline red mud modified biochar & rice straw & 5923.8 & This work \\
hematite modified biochar & loblolly pine(Pinus taeda) wood & 428.7 & Wang et al.(2015a) \\
$\mathrm{MnCl}_{2} \cdot 4 \mathrm{H}_{2} \mathrm{O}$ modified biochar & pine wood & 590 & Wang et al.(2015b) \\
birnessite modified biochar & pine wood & 910 & Wang et al.(2015b) \\
$\mathrm{Fe}$ coated biochars & empty fruit bunch & 15200 & Samsuri et al.(2013) \\
$\mathrm{Fe}$ coated biochars & rice husk & 16900 & Samsuri et al.(2013) \\
La loaded Biochar & corn stalk & 38020 & Feng et al. (2015) \\
Red mud & & 941 & Altundogan et al. (2000) \\
\hline
\end{tabular}

566

567

568

569

570

571

572

573

574

575

576

577

578

579 

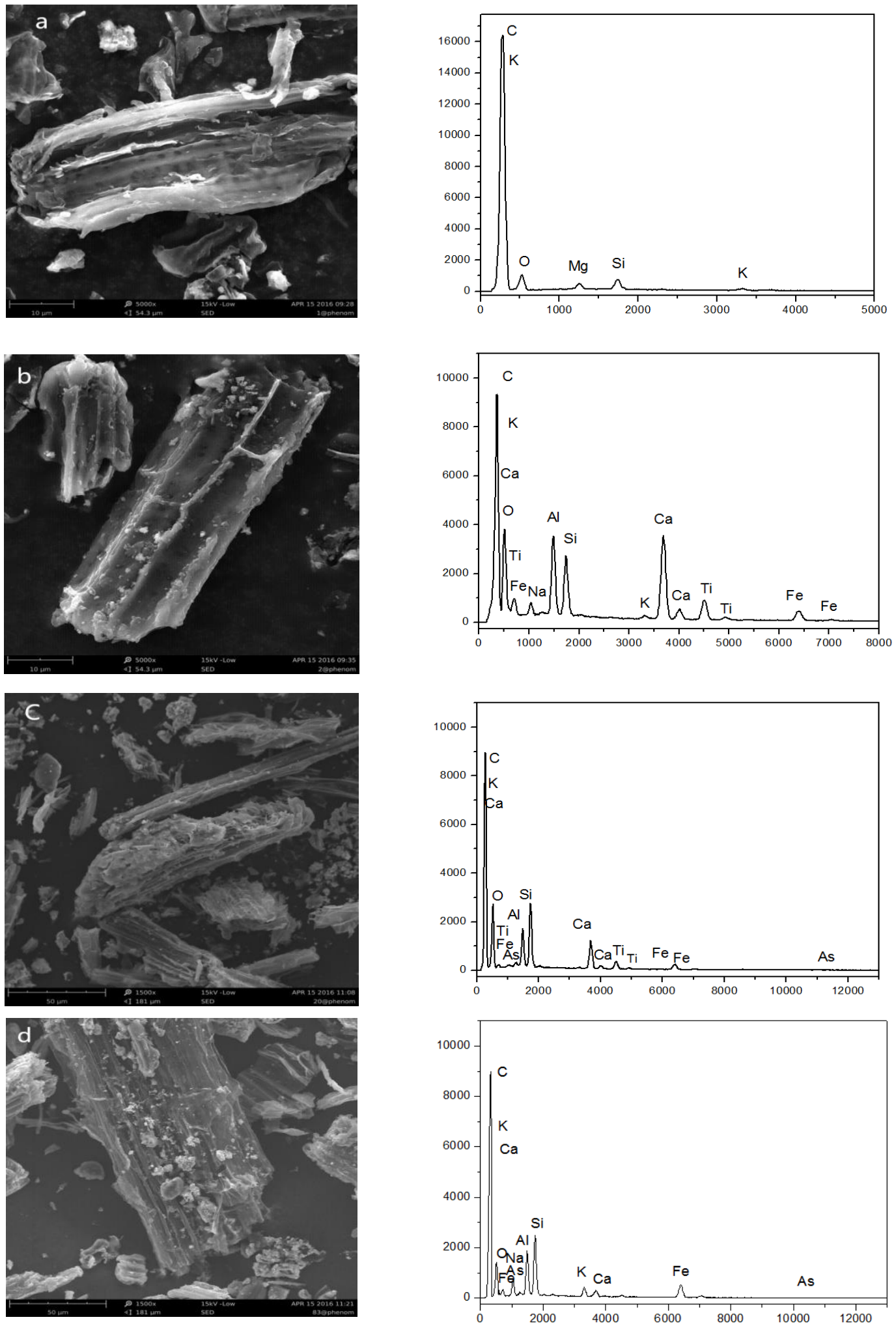

Fig. 1. SEM-EDS of biochar (BC) and red mud-modified biochar (RM-BC): a. BC, b.

581 RM-BC before adsorption; c. RM-BC after adsorption of As(V), d. RM-BC after adsorption of 582 As(III). 


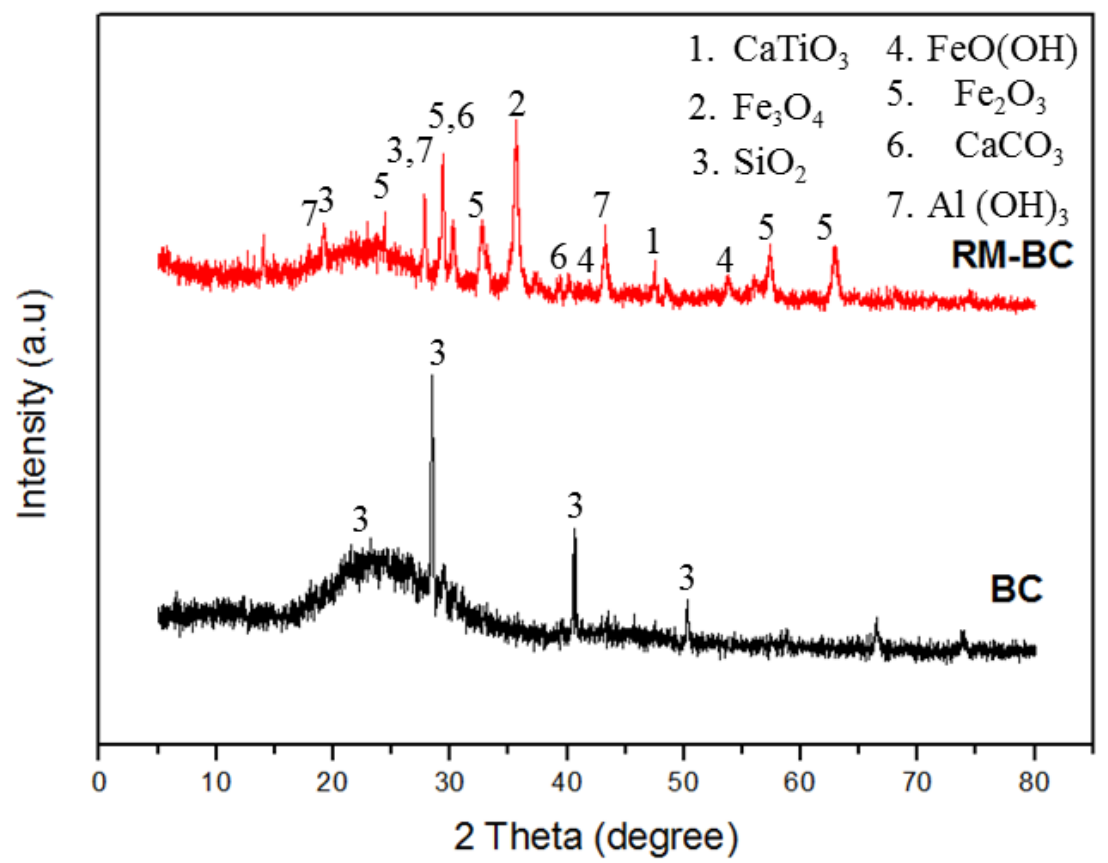

583

Fig. 2. X-ray diffraction spectra of biochar (BC) and red mud-modified biochar (RM-BC). 

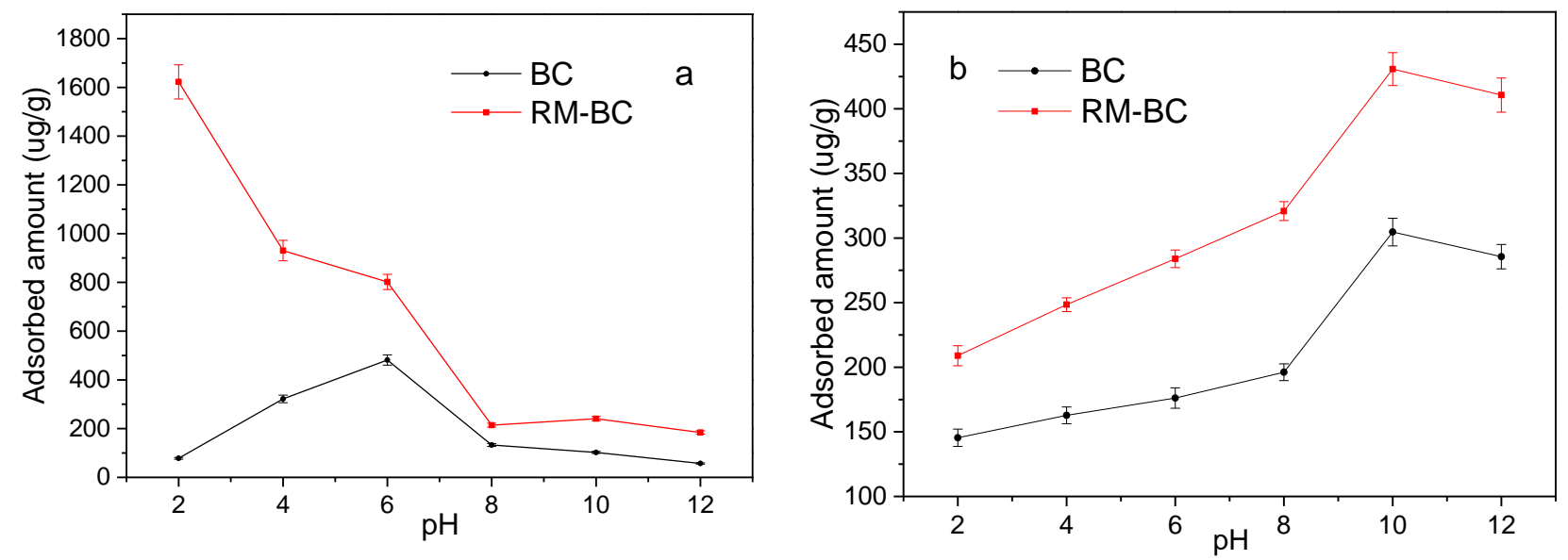

598 Fig. 3. Effect of $\mathrm{pH}$ on the concentration of (a) $\mathrm{As}(\mathrm{V})$ and (b) $\mathrm{As}(\mathrm{III})$ adsorbed by $\mathrm{BC}$ and 599 RM-BC.

600

601

602

603

604

605

606

607

608

609

610

611

612

613 

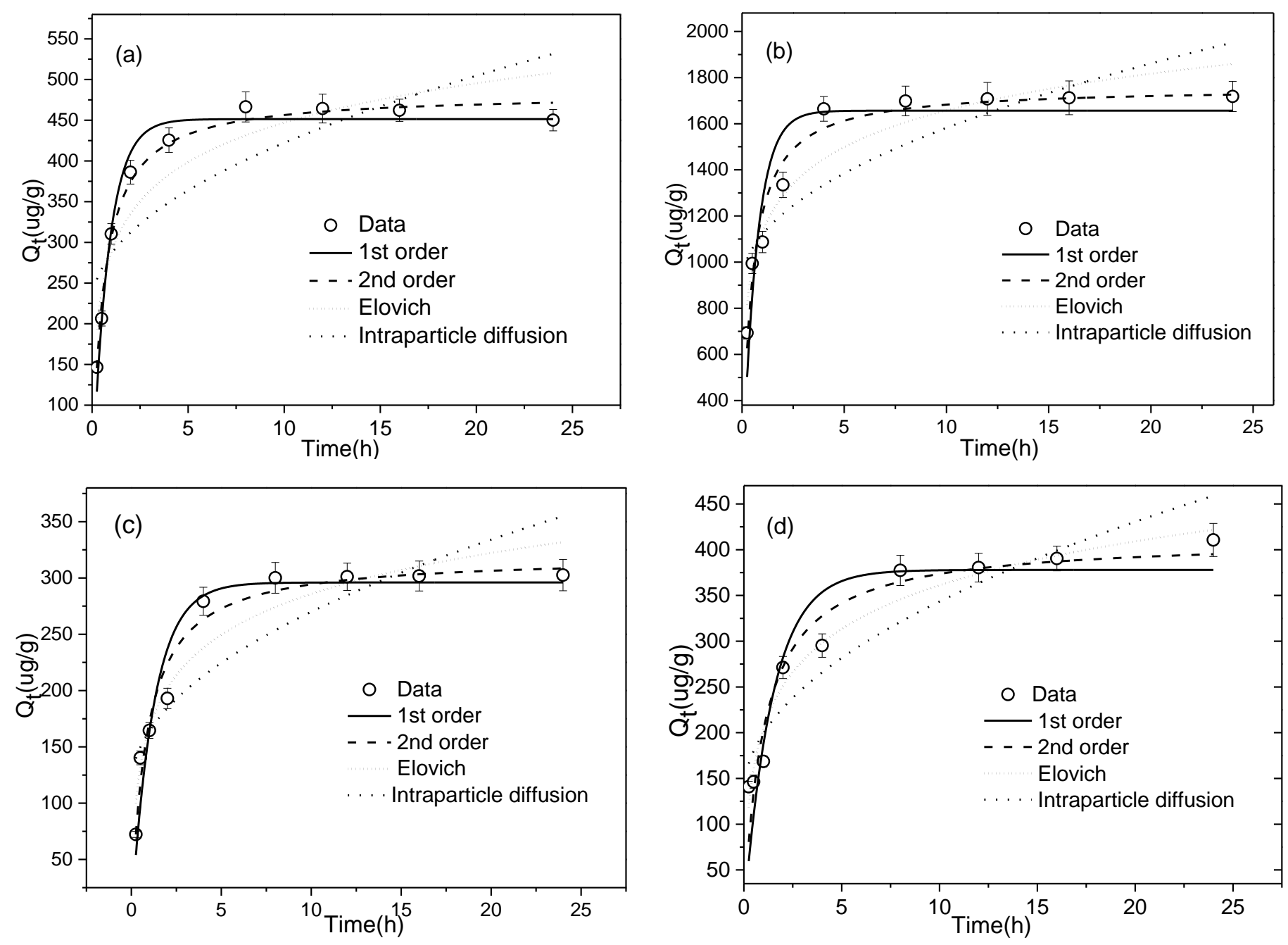

614 Fig. 4. Adsorption kinetics and modeling for As on adsorbents: (a) and (b) are As(V) adsorption on

615 BC and RM-BC respectively. (c) and (d) are As(III) adsorption on BC and RM-BC respectively. 

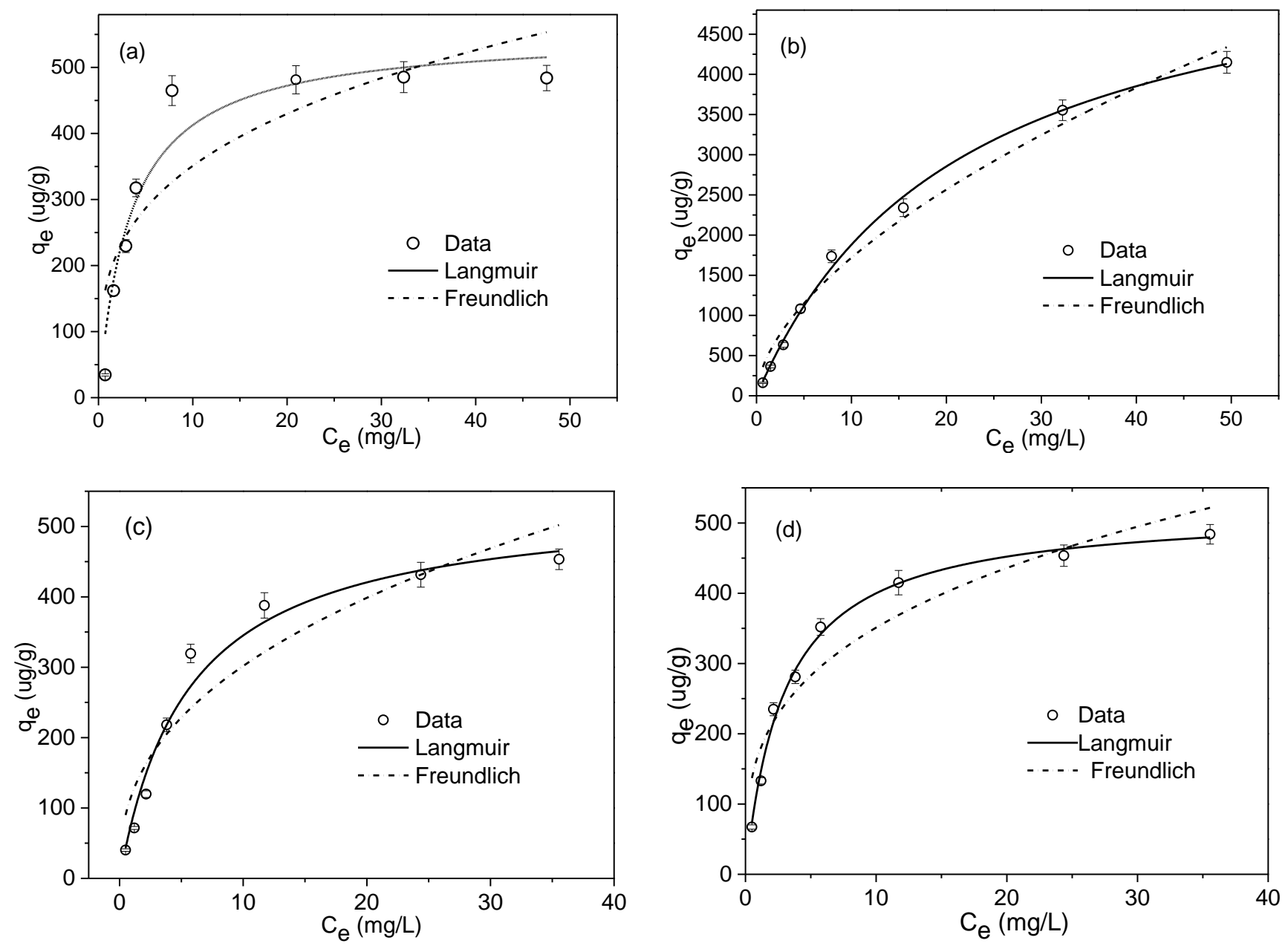

623 Fig. 5. Adsorption isotherm data and modeling for As on adsorbents: (a) and (b) are As(V)

624 adsorption on BC and RM-BC respectively. (c) and (d) are As(III) adsorption on BC and RM-BC

625 respectively.

626

627

628

629

630 

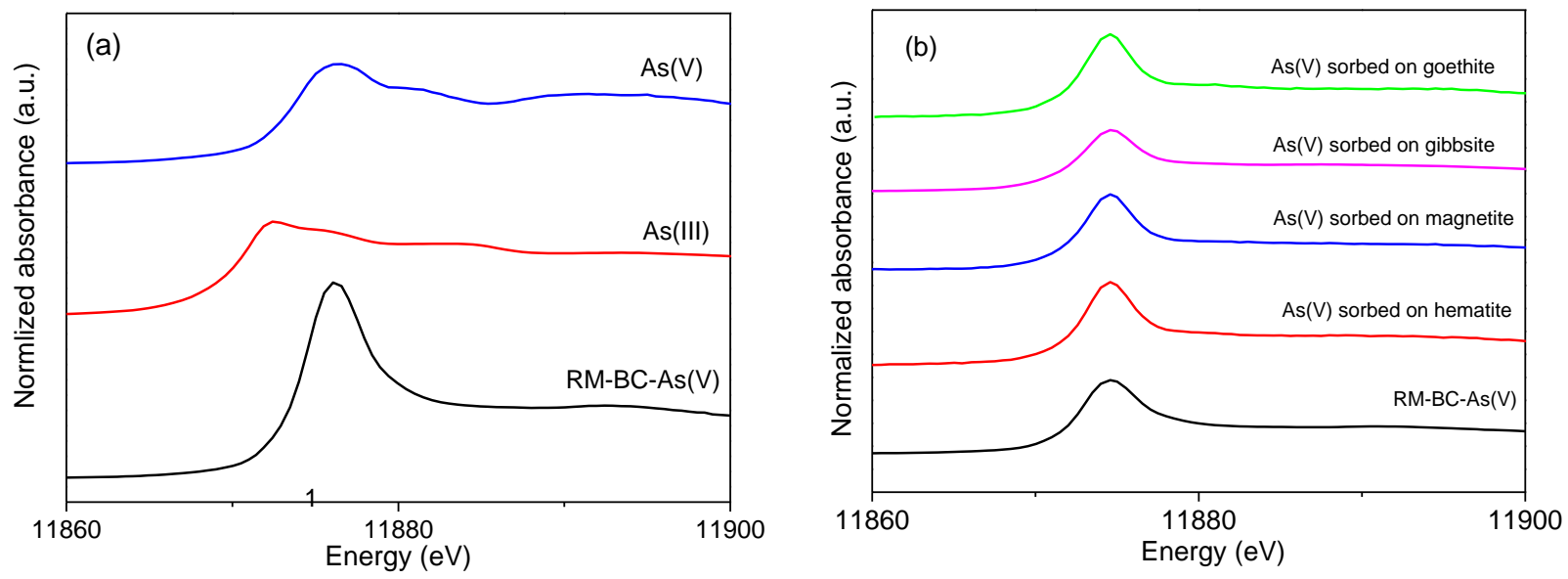

Fig. 6. Normalized As k-edge X-ray absorption near-edge structure (XANES) spectra for As(V)

632 adsorption on RM-BC (a) the percentages of As species; (b) the percentages of As adsorbed on 633 different minerals; All fit parameters are detailed in Table 3. 
670

671

672

673

674

675

676

677

678

679

680

681

682

683

684

685

686

687

688

689

690

691

692
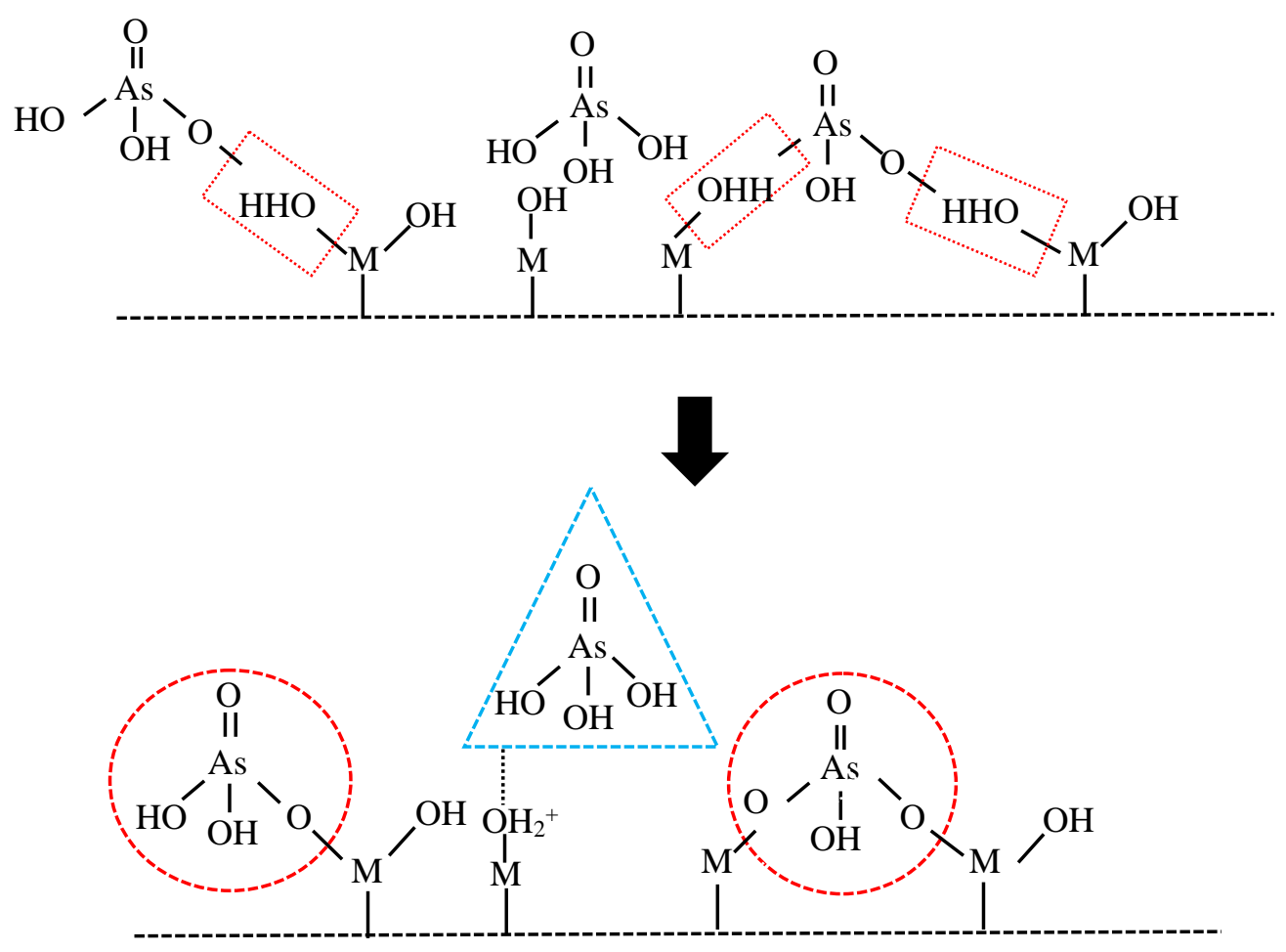

Fig. 7. Mechanism of $\mathrm{As}(\mathrm{V})$ adsorption on red mud-modified biochar, where $\mathrm{M}$ is the metal oxide composition of the red mud surface. 


\section{Table and figure legends}

Table 1 Kinetic models and best-fit parameter values for $\mathrm{As}(\mathrm{V})$ and $\mathrm{As}(\mathrm{III})$ adsorption data.

Table 2 Isotherm models and best-fit parameter values for $\mathrm{As}(\mathrm{V})$ and $\mathrm{As}(\mathrm{III})$ adsorption data.

Table 3 SPOIL values of references obtained by target transformation (TT), and linear combination fit ( $\mathrm{LCF})$ results of $\mathrm{As}(\mathrm{V})$ adsorption on $\mathrm{RM}-\mathrm{BC}$.

Table 4 Comparison of the adsorption capacities of different adsorbents for As(V).

Fig. 1. SEM-EDS of biochar (BC) and red mud-modified biochar (RM-BC): a. BC, b. RM-BC before adsorption; c. RM-BC after adsorption of As(V), d. RM-BC after adsorption of As(III).

Fig. 2. X-ray diffraction spectra of biochar (BC) and red mud-modified biochar (RM-BC).

Fig. 3. Effect of $\mathrm{pH}$ on the concentration of (a) $\mathrm{As}(\mathrm{V})$ and (b) $\mathrm{As}(\mathrm{III})$ adsorbed by BC and RM-BC.

Fig. 4. Adsorption kinetics and modeling for As onto adsorbents: (a) and (b) are As(V) adsorption on $\mathrm{BC}$ and $\mathrm{RM}-\mathrm{BC}$ respectively. (c) and (d) are $\mathrm{As}(\mathrm{III})$ adsorption on $\mathrm{BC}$ and $\mathrm{RM}-\mathrm{BC}$ respectively.

Fig. 5. Adsorption isotherm data and modeling for As onto adsorbents: (a) and (b) are $\mathrm{As}(\mathrm{V})$ adsorption on BC and RM-BC respectively. (c) and (d) are $\mathrm{As}(\mathrm{III})$ adsorption on $\mathrm{BC}$ and $\mathrm{RM}-\mathrm{BC}$ respectively.

Fig. 6. Normalized As k-edge X-ray absorption near-edge structure (XANES) spectra for As(V) adsorption on RM-BC (a) the percentages of As species; (b) the percentages of As adsorbed on different minerals; All fit parameters are detailed in Table 3.

Fig. 7. Mechanism of $\mathrm{As}(\mathrm{V})$ adsorption on red mud-modified biochar, where $\mathrm{M}$ is the metal oxide composition of the red mud surface. 